\title{
Sensing Organophosphorus Compounds with SWCNT Films
}

\author{
Mika Sahlman ${ }^{1}$, Mari Lundström ${ }^{1}$ and Dawid Janas ${ }^{2, *(\mathbb{D}}$ \\ 1 Hydrometallurgy and Corrosion, Department of Chemical and Metallurgical Engineering (CMET), School of \\ Chemical Engineering, Aalto University, P.O. Box 16200, 00076 Aalto, Finland; mika.sahlman@aalto.fi (M.S.); \\ mari.lundstrom@aalto.fi (M.L.) \\ 2 Department of Organic Chemistry, Bioorganic Chemistry and Biotechnology, Silesian University of \\ Technology, B. Krzywoustego 4, 44-100 Gliwice, Poland \\ * Correspondence: Dawid.Janas@polsl.pl; Tel.: +48-32-237-10-82
}

Citation: Sahlman, M.; Lundström, M.; Janas, D. Sensing

Organophosphorus Compounds with SWCNT Films. Sensors 2021, 21, 4915. https://doi.org/10.3390/s21144915

Academic Editors: Mohammad Nur-E-Alam, Mikhail Vasiliev and Mohsin Ali Badshah

Received: 18 June 2021

Accepted: 16 July 2021

Published: 19 July 2021

Publisher's Note: MDPI stays neutral with regard to jurisdictional claims in published maps and institutional affiliations.

\begin{abstract}
Promising electrical properties of single-walled carbon nanotubes (SWCNTs) open a spectrum of applications for this material. As the SWCNT electronic characteristics respond well to the presence of various analytes, this makes them highly sensitive sensors. In this contribution, selected organophosphorus compounds were detected by studying their impact on the electronic properties of the nanocarbon network. The goal was to untangle the n-doping mechanism behind the beneficial effect of organic phosphine derivatives on the electrical conductivity of SWCNT networks. The highest sensitivity was obtained in the case of the application of 1,6-Bis(diphenylphoshpino)hexane. Consequently, free-standing SWCNT films experienced a four-fold improvement to the electrical conductivity from $272 \pm 21$ to $1010 \pm 44 \mathrm{~S} / \mathrm{cm}$ and an order of magnitude increase in the power factor. This was ascribed to the beneficial action of electron-rich phenyl moieties linked with a long alkyl chain, making the dopant interact well with SWCNTs.
\end{abstract}

Keywords: phosphines; single-walled carbon nanotubes; doping

\section{Introduction}

The discovery of carbon nanomaterials such as carbon nanotubes (CNTs) [1,2] and graphene [3] created new perspectives for materials science. Ever since the remarkable electrical [4-6], mechanical [7-9], thermal [10-12], and optical [13-16] characteristics were first observed, the research community focused efforts to apply these nanostructures in a broad spectrum of applications. Due to their favorable electrical and mechanical properties, able to offer simultaneously high strength and flexibility [17,18], they became particularly interesting components for flexible electronics or low grade heat harvesting [19].

However, the key problem with making these goals reality is that translation of the properties from the nano realm to the real-life scale is non-trivial. Macroscopic assemblies in the form of fibers and thin films made from carbon nanostructures experience the so-called contact resistance, which very much limits their electrical conductivity [20]. Charge transport at the boundaries of individual CNTs or graphene flakes making up the ensemble increases its resistance considerably. Furthermore, the isotropic distribution of these building blocks within the network contributes its share to the extrinsic component of resistance, which must be considered. Recent advances in the field alleviate these problems by substantially improving the internal structure alignment [21-24]. Nevertheless, the intrinsic factors of resistance remain a problem.

To overcome this issue and enhance the electrical conductivity of networks based on nanocarbon structures, one also needs to focus on the building blocks themselves. This aim can be accomplished by, e.g., improving the crystallinity of the $\mathrm{C}\left(\mathrm{sp}^{2}\right)$ lattice or adding dopants able to boost the charge transport characteristics. Their presence impacts the Fermi level of the material in a similar fashion, thereby improving their opportunities for commercialization by making the CNTs more conductive. 
Single-walled CNTs (SWCNTs) are amphoteric, which means that they can donate or accept electrons to become $\mathrm{p}$ - and $\mathrm{n}$-doped, respectively $[25,26]$. A wide range of chemical compounds can be employed for this purpose. The first class encompasses electron-poor species such as mineral acids $[27,28]$ or halogens $[29,30]$. On the other hand, the latter group typically comprises amines and their derivatives [31,32] or alkali metals [29,33].

An interesting category of electron-rich dopants was illustrated by Nonoguchi et al., who showed that phosphorus-bearing chemical compounds can act as powerful n-dopants with doping strength dependent on the molecular structure [34]. Addition of these species to SWCNT films considerably improved their electrical and thermoelectric properties. One of the most auspicious phosphorus dopants explored therein was 1,3-Bis(diphenylphosphino) propane. It gave enhanced conductivity from 36 to $100 \mathrm{~S} / \mathrm{cm}$ and changed the Seebeck coefficient of the SWCNT network from +49 to $-52 \mu \mathrm{V} / \mathrm{K}$. The observed sign reversal was proof that the material was strongly $n$-doped. Simultaneously, pollution of the environment with phosphorous bears a number of critical consequences. It is one of the most widespread pollutants in water [35]. It affects $66 \%$ of river streams and $42 \%$ of lakes in the Unites States alone [36]. Consequently, the water quality is subject of eutrophication leading to mortality of flora and fauna $[37,38]$.

In this work, we studied how the presence of phosphorus may be monitored by the application of electrically conducting sensors from SWCNT films. So far, similar SWCNT ensembles have been employed for sensing alcohols [39], $\mathrm{NH}_{3}$ [40], $\mathrm{NO}_{2}$ [41], and volatile organic chemicals (VOCs) [42], etc. [43]. Herein, the aim was to resolve the critical structural features of an organophosphorus compound to make the detection by the SWCNTs the strongest. A selection of model organic phosphine derivatives was employed: 1,3-Bis(dimethylphosphino)propane (linear alkyl substitution on $\mathrm{P}$ atom), 1,3-Bis(dicyclohexylphosphino)propane (cyclic alkyl substituent on $\mathrm{P}$ atom), and 1,3-Bis(diphenylphosphino)propane (aryl substituent on P atom). The impact of length of the alkylene group was studied using 1,6-Bis(diphenylphosphino)hexane. The change of microstructure/purity of the SWCNT films upon doping was analyzed. Then, electrical conductivity, Seebeck coefficients, and power factors were established. Finally, modeling the electronic density distribution of the dopants enabled us to hypothesize the structure of an organophosphorus most sensitively detected by SWCNTs.

\section{Materials and Methods}

\subsection{Compounds and Materials}

Large-diameter SWCNTs (Tuball ${ }^{\mathrm{TM}}$; OCSiAl, Leudelange, Luxembourg) were evaluated in the form of ensembles. The following organophosphorus dopants were used: 1,3Bis(dimethylphosphino)propane (dmpp), 1,3-Bis(dicyclohexylphosphino)propane (dcpp), 1,3-Bis(diphenylphosphino)propane (dpp), 1,6-Bis(diphenylphosphino)hexane (dpph). All of them were procured from Sigma-Aldrich (St. Louis, MO, USA). Acetone and toluene engaged as a medium for preparing SWCNT networks were obtained from Avantor, Gliwice, Poland. Ag conductive paint (SCP03B; Electrolube, Ashby-de-la-Zouch, UK) was employed to prepare specimens for characterization of their electrical conductivity.

\subsection{Manufacture of Free-Standing SWCNT-Based Films}

SWCNT films were manufactured by a technique developed in-house [44]. The difference between the reference and the newly reported approach is that a different class of doping agents was used herein to elucidate the mechanism of their action (Figure 1).

Briefly, $150 \mathrm{mg}$ of SWCNTs kept in a desiccator were added to $80 \mathrm{~mL}$ of acetone and toluene mixture (1:1 by weight). Then, an appropriate amount of the above-mentioned doping agents was introduced to establish a $0.1 \mathrm{M}$ concentration in this medium (for sensitivity experiments the concentration was varied from $0.001 \mathrm{M}$ to $1 \mathrm{M}$ for $\mathrm{dpph}$ ). 

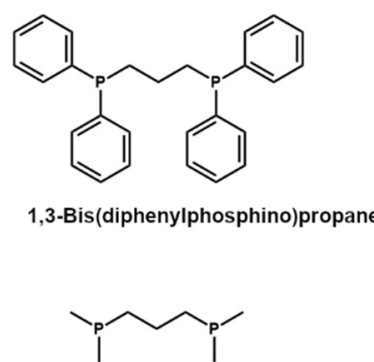

Bis(dimethylphosphino)propane

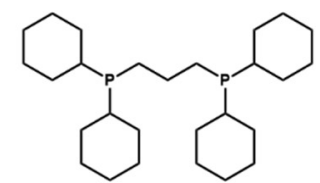

1,3-Bis(dicyclohexylphosphino)propane<smiles>c1ccc(CCCCCCC(c2ccccc2)c2ccccc2)cc1</smiles>

1,6-Bis(diphenylphosphino)hexane

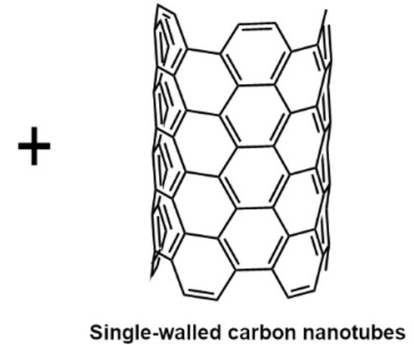

1. Sonication

2. Vacuum filtration

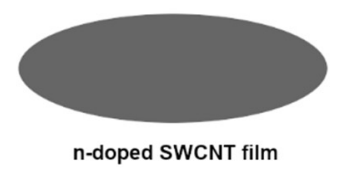

Figure 1. Manufacture of n-doped SWCNT films by vacuum filtration in the presence of organophosphorus compounds.

Afterward, the mixture was homogenized by ultrasonication at $100 \%$ amplitude (UP200St sonicator; Hielscher, Teltow, Germany) for 10 min over an ice bath. Such an amount of time was sufficient to reach a uniform dispersion. It was filtered under reduced pressure using PTFE membrane filters (pore size: $0.45 \mu \mathrm{m}$, diameter: $47 \mathrm{~mm}$; Fisherbrand, Ottawa, ON, Canada). Due to the low adhesion of SWCNT films to PTFE, they were easily peeled off the surface. Dopant-free SWCNT films were also made as a reference.

\subsection{Characterization}

Raman spectroscopy (inVia Renishaw system, Wotton-under-Edge, UK) was used to gauge the structural perfection of SWCNTs and the impact of doping on the electronic characteristics. The spectra were acquired at the excitation wavelength of $\lambda=633 \mathrm{~nm}$ from 100 to $3000 \mathrm{~cm}^{-1}$. Laser power was kept to the minimum $(0.01 \%$ total power $)$ to ensure that the sample was not heated by absorption of radiation [32]. Mean values of $\mathrm{I}_{\mathrm{D}} / \mathrm{I}_{\mathrm{G}}$ ratios with established standard deviations are reported along with the position of the $\mathrm{G}^{+}$component to study the doping effect. Multiple acquisitions at different locations of the samples eliminated the possible impact of sample inhomogeneity and background noise, respectively.

Scanning electron microscope (SEM, JEOL JSM-7500FA, Tokyo, Japan) visualized the microstructure of the SWCNT films before and after doping. The experiments were conducted at the acceleration voltage of $15 \mathrm{kV}$. The material was well conductive, so it was not sputtered with metal for imaging.

The electrical conductivity of the SWCNT films was gauged in a four-terminal configuration. The specimens $(3 \mathrm{~mm} \times 40 \mathrm{~mm})$ were cut out from the SWCNT films obtained after filtration. Then, they were attached to custom-designed sample holders. The terminals were made of $\mathrm{Cu}$ to give current-carrying and voltage-sensing pairs. To ensure no issues with electrical and mechanical contact between SWCNTs and $\mathrm{Cu}$, Ag conductive paint (SCP03B; Electrolube, Ashby-de-la-Zouch, UK) was applied at the interface. A source meter (Keithley 2450 SourceMeter, Cleveland, OH, USA) measured the conductivity in this 
setup. Conductance was recalculated to conductivity by taking into account the samples' dimensions. The thickness was measured with a micrometer screw gauge (Electronic Universal IP54, Linear Tools, Dunstable, UK).

Seebeck coefficients of the materials were obtained using a custom-made apparatus (SeebCam, LBR, Lublin, Poland) across the $30-100{ }^{\circ} \mathrm{C}$ temperature range. The samples were mounted on a board enclosed in a sealed chamber free of air to minimize the effect of convection. The ends of the samples were then put in contact with resistive heaters and temperature sensors, which established a temperature gradient and monitored the temperature, respectively. The difference in electric potential was measured at the temperature gradient of $5{ }^{\circ} \mathrm{C}$. The reported values were averaged across the indicated temperature range. In all the cases, multiple measurements were conducted to ensure the statistical significance of the obtained data.

Molecular models of the dopants were drawn by Avogadro: an open-source molecular builder and visualization tool [45]. The structures were optimized in Universal Force Field (UFF). Gaussian 09W (B3LYP/6-31G(d) model) was used to approximate the atomic charges and thus the electron densities of the molecules under investigation in Avogadro.

\section{Results}

We began the analysis by investigating the crystallinity of evaluated SWCNT networks by Raman spectroscopy (Figure 2). The SWCNT present in the parent unmodified material (Figure 2a) manifested typical features such as the radial breathing mode (RBM) (indicative of single- or double-walled character of the sample) as well as D (corresponding to sp ${ }^{3}$ carbon atoms), $\mathrm{G}$ (stemming from the presence of $\mathrm{sp}^{2}$ carbon atoms), and $\mathrm{G}^{\prime}$ bands. What is more, a clear split of the G band into G- and G+ components was observed (Figure 2b), which confirmed that the material was of single-walled character [46].

(a)

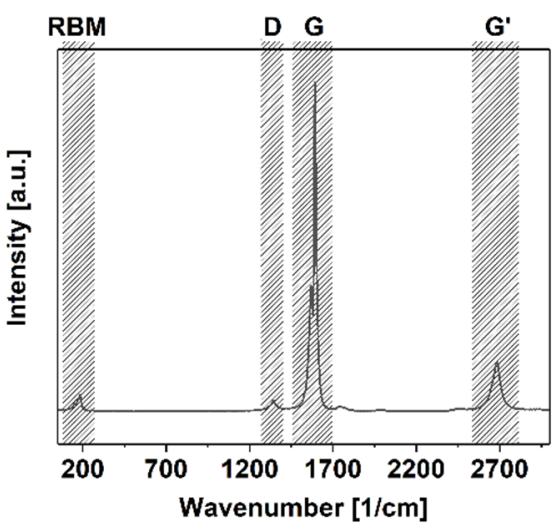

(c)

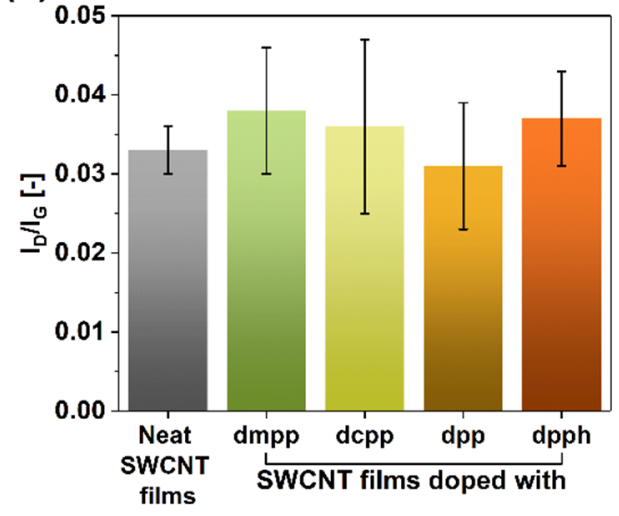

(b)

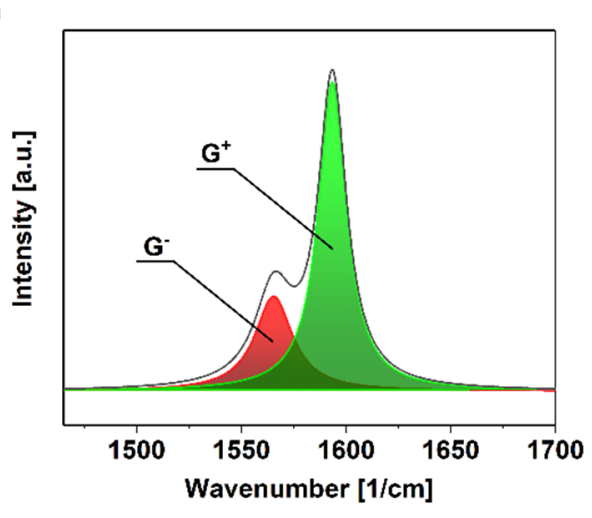

(d)

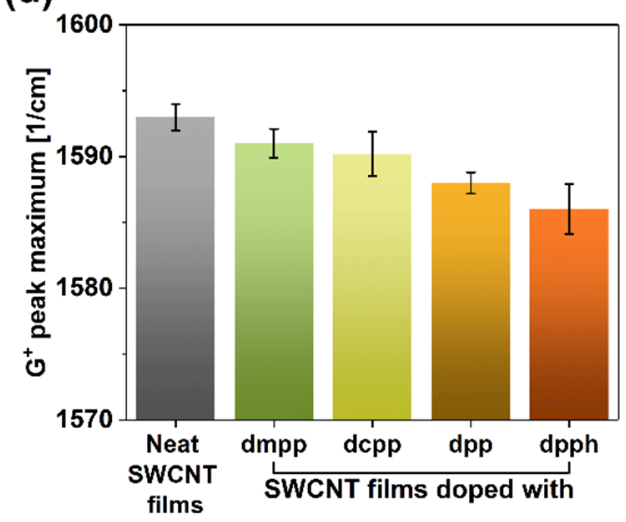

Figure 2. (a) Full Raman spectrum of a neat SWCNT film, (b) magnification of the G peak area with exemplary deconvolution into G- and G+ components, (c) $\mathrm{I}_{\mathrm{D}} / \mathrm{I}_{\mathrm{G}}$ ratios of SWCNT films before and after doping, and (d) corresponding recorded positions of G+ peak maxima after deconvolution. 
One of the most straightforward techniques of estimating the purity of SWCNTs is to establish the $\mathrm{I}_{\mathrm{D}} / \mathrm{I}_{\mathrm{G}}$ ratio, which quantifies the relative amount of impurities ( $\mathrm{sp}^{3}$ carbon atoms from SWCNT defects or non-SWCNT carbon to D feature intensity) to pristine SWCNT material ( $\mathrm{sp}^{2}$ carbon atoms to G feature intensity) [46]. Firstly, the results obtained in this study showed that the starting material was pristine as the $\mathrm{I}_{\mathrm{D}} / \mathrm{I}_{\mathrm{G}}$ ratio was as low as $0.033 \pm 0.003$ (Figure 2c). Secondly, upon introducing the dopants, neither of the samples exhibited a statistically significant increase in the D-band intensity. Instead, the values of the $\mathrm{I}_{\mathrm{D}} / \mathrm{I}_{\mathrm{G}}$ ratios stayed within the $0.031-0.038$ range, so the dopant-SWCNT interactions are physical rather than chemical. The slight discrepancy can be assigned to the measurement error since the intensity of the D-peak was very low.

More insight regarding the action of the dopants on the SWCNTs can be obtained from the analysis of the position of the G+ peak maxima [47]. According to the literature, when a red-shift of this feature occurs, it indicates an upwards shift to the Fermi level caused by n-doping. While the $\mathrm{G}+$ peak maximum was at $1593 \mathrm{~cm}^{-1}$ for the untreated material, once organophosphorus dopants were introduced to the network, a clear red-shift was observed (Figure 2d). The addition of dmpp, dcpp, dpp, and dpph moved the G+ peak maximum to $1591,1590,1588$, and $1586 \mathrm{~cm}^{-1}$, respectively. Based on these measurements, dpph appeared as the strongest dopant, as it repositioned this feature by as much as $7 \mathrm{~cm}^{-1}$. This is noteworthy as SWCNTs are naturally p-doped by oxygen in the ambient [48], so the specific dopant had to be powerful enough to overcome this effect.

Furthermore, SEM imaging was conducted to probe for possible changes to the microstructure of the material upon dopant addition (Figure 3). The neat SWCNT film (Figure 3a) showed isotropic structure as anticipated for buckypapers made by filtration. The material was arranged into bundles of a considerable number of SWCNTs. The employed SWCNTs had an average diameter of $1.6 \mathrm{~nm}$, while the diameter of the bundles reached up to hundreds of nanometers. No impurities could be discerned in the images.

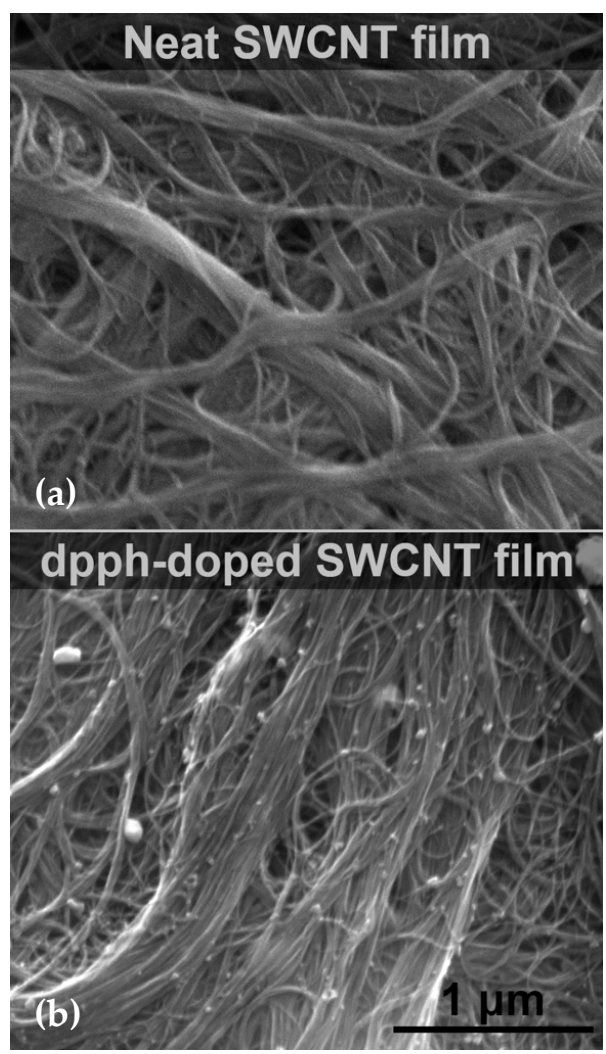

Figure 3. SEM micrographs of (a) neat SWCNT film and (b) upon doping with dpph. 
Upon doping the SWCNT film with dpph, which showed the most substantial shift to the G+ peak maximum, there was no obvious change to the alignment or porosity of the ensemble (Figure $3 b$ ). The only difference was the presence of dpph molecules, which are solid at room temperature, so they were visualized on the surface. It should be noted that the dopant particles were well dispersed throughout the structure of the material, which can already partially explain why the observed doping was so effective (vide infra).

The electrical and thermoelectric properties of the SWCNT films were measured to study this effect in more detail (Figure 4). The electrical conductivity of the parent material was at the level of $251 \pm 12 \mathrm{~S} / \mathrm{cm}$, which matches the values reported in the literature [19] (Figure 4a). The introduction of the organophosphorus dopants clearly enhanced this parameter. While the addition of dmpp or dcpp caused the electrical conductivity to increase to $272 \pm 21$ and $367 \pm 27 \mathrm{~S} / \mathrm{cm}$, much more tangible benefits brought the introduction of dpp or dpph. In these cases, the electrical conductivity was enhanced to $744 \pm 34$ and $1010 \pm 44 \mathrm{~S} / \mathrm{cm}$, respectively. Therefore, the addition of dpph at the point of SWCNT film formation managed to cause a four-fold boost to this property. The extent to which the electrical conductivity was increased paralleled the magnitude of the $\mathrm{G}+$ peak shift.

\section{(a)}

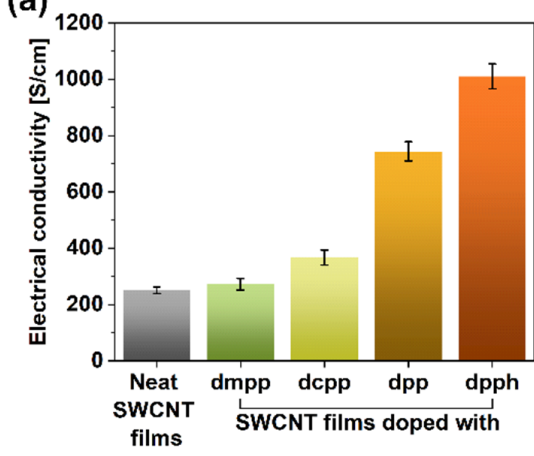

(b)

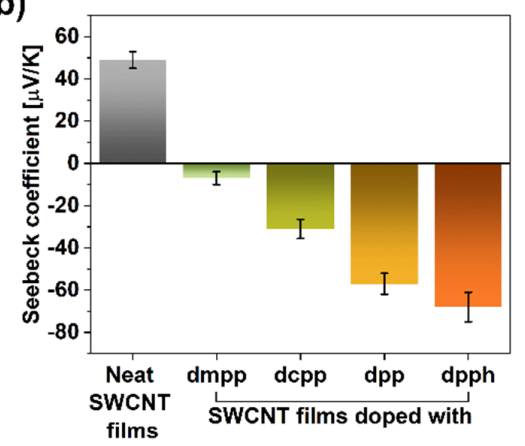

(c)

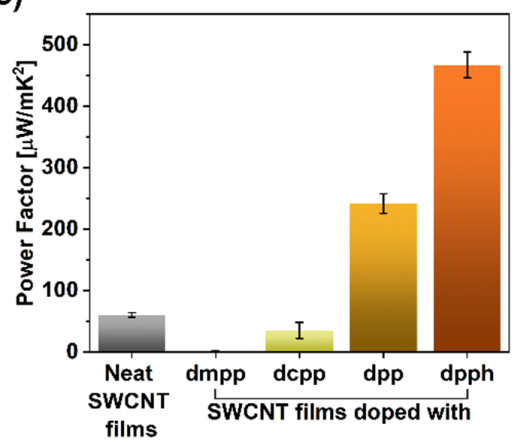

Figure 4. (a) Electrical conductivity values, (b) Seebeck coefficients, and (c) power factors of the SWCNT films before and after doping with organophosphorus compounds. 
The measurement of Seebeck coefficients showed that once the organophosphorus compounds were introduced, the charge transport within the material became dominated by electrons (displayed by the sign change of the Seebeck coefficients; Figure 4b) following previous findings [34]. Notably, the addition of dpph changed the Seebeck coefficient from +49 (starting SWCNTs) to $-68 \mu \mathrm{V} / \mathrm{K}$ (doped SWCNTs), which once again proved a strong influence of these doping species in particular.

A measure that can gauge a material's suitability to act as a thermogenerator is the socalled power factor (PF). It considers the electrical conductivity $(\sigma)$ and Seebeck coefficient $(\alpha)$ while neglecting the impact of thermal conductivity. It is quantified according to the following formula: $\mathrm{PF}=\alpha^{2} \cdot \sigma$. The PF values for all the evaluated dopants are established in Figure 4c.

Colossal changes to the capability of the material to generate thermopower were witnessed. The PF value of the parent material, which was $60.27 \mu \mathrm{W} / \mathrm{m} \cdot \mathrm{K}^{2}$, decreased to a mere $1.44 \mu \mathrm{W} / \mathrm{m} \cdot \mathrm{K}^{2}$ for the sample doped with dmpp. On the other hand, once dpph was added, one order of magnitude increase was observed. As a result, the PF value of $467 \mu \mathrm{W} / \mathrm{m} \cdot \mathrm{K}^{2}$ was recorded for such formulation, which is among the highest thermoelectric performance reported so far [19]. This encouraging improvement was caused by the synergistic action of electrical conductivity and Seebeck coefficient, both of which increased considerably after the treatment. Analogously, the deterioration of the thermoelectric capabilities for SWCNT samples doped with dmpp and dcpp resulted from the decrease of Seebeck coefficients, which have a quadratic impact on the PF values.

Molecular models with electron densities were calculated (Figure 5) to decipher the radically different influence of various organophosphorus compounds explored in this work). Firstly, the addition of dmpp caused only slight improvement to the electrical conductivity, while the Seebeck coefficient was very much reduced. Among the explored dopants, this was the only aliphatic and acyclic member, which suggests that such characteristics cannot provide the proper dopant-SWCNT interaction necessary to enhance the electrical and thermoelectric properties of the material. Furthermore, according to the calculated electron densities, the negative charge is localized at the phosphorus atoms, which is not optimal (vide infra). On the other hand, dcpp, also an aliphatic compound, could generate a negative charge away from phosphorus atoms. This modification already resulted in moderate improvement to the electrical conductivity and made the Seebeck coefficient of SWCNTs more negative. However, a substantial boost to these parameters was obtained only when the organophosphorus dopants (dpp and dpph) were equipped with phenyl groups, where the negative charge was concentrated. Such functional groups can interact well with the surface of SWCNTs by van der Waals forces $(\pi-\pi$ interactions, in particular). With this in mind, the charge needs to be effectively donated to the SWCNTs for the doping to be potent. Lastly, the performance of dpph was substantially better than that of dpp. We hypothesize that the six methylene groups in dpph give more flexibility to the dopant. Consequently, such doping species can assume a conformation promoting the interactions between the negatively charged phenyl groups and the SWCNT side-wall. The difference in electron density distribution between dpp and dpph may be disregarded from consideration. For both the dopants, the amount of negative charge in the phenyl substituents is indistinguishable. 

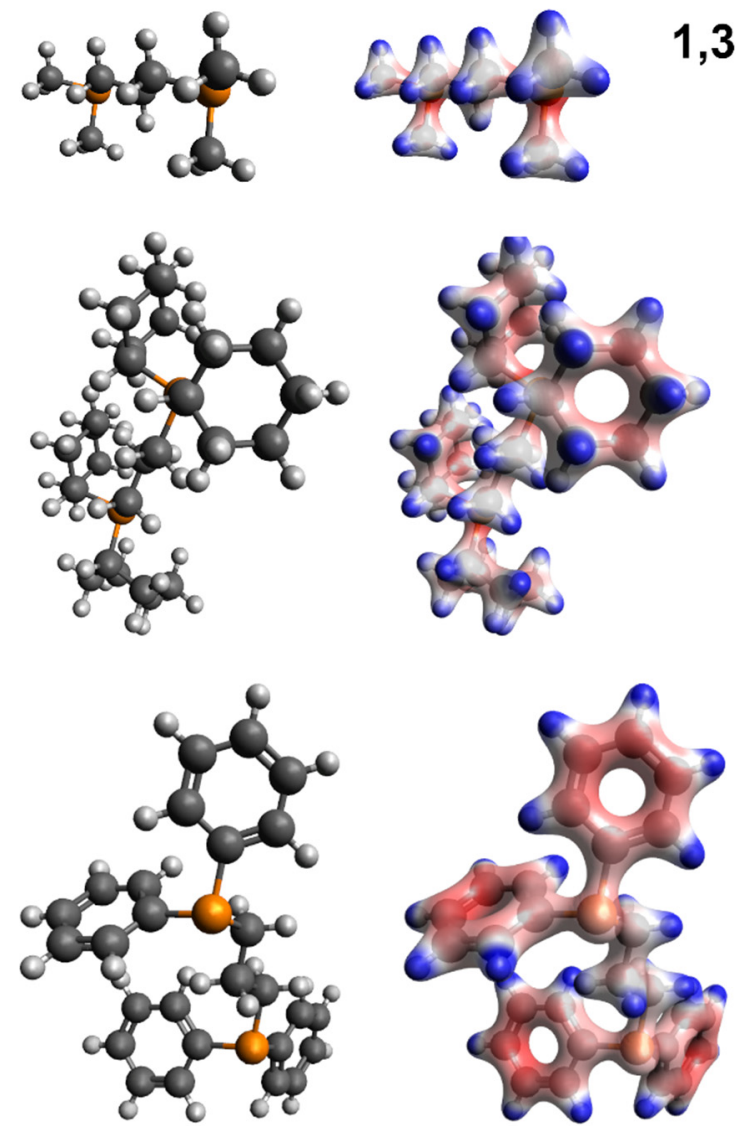

\section{1,3-Bis(diphenyl- -phosphino)propane (dpp)}

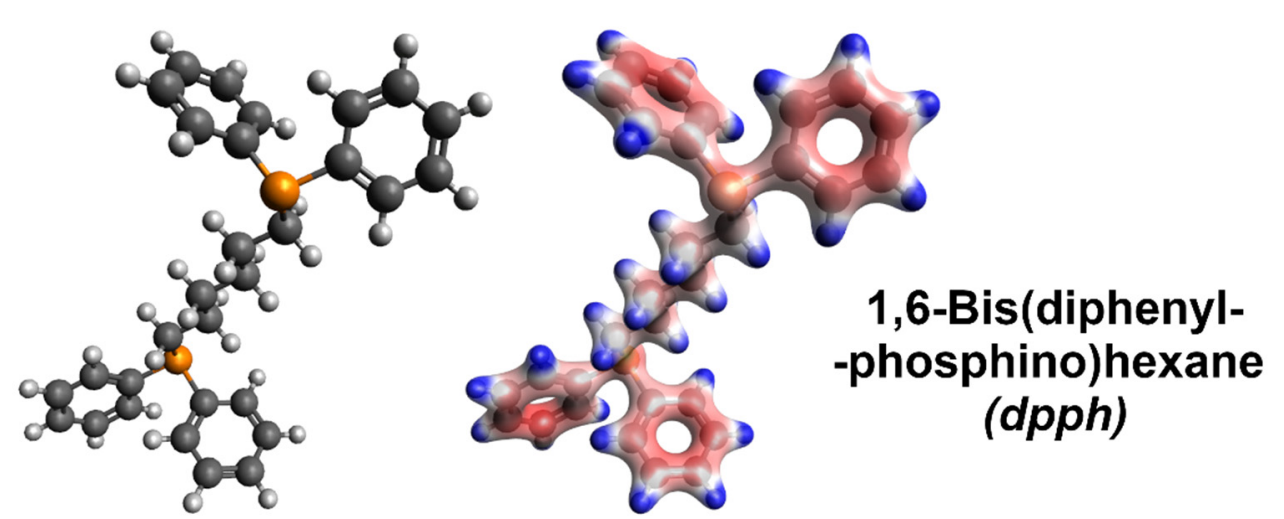

Figure 5. Left column: bare molecular models of the organophosphorus dopants (grey—carbon, white—hydrogen, and orange-phosphorus). Right column: corresponding molecular models with electron densities overlaid obtained by computation (red-negative charge and blue-positive charge).

Lastly, the sensitivity of SWCNT films towards detection of organophosphorus compounds was evaluated using dpph across a $0.001 \mathrm{M}-1 \mathrm{M}$ concentration range (Figure 6). Tangible change in electrical conductivity from $251 \pm 12$ to $311 \pm 32 \mathrm{~S} / \mathrm{cm}$ can already be detected at the lowest dopant concentration of $0.001 \mathrm{M}$. As the concentration of dpph is elevated, a linear increase in conductivity is evident up to $0.1 \mathrm{M}$ concentration. Above this point, only negligible enhancement of electrical conductivity is observed indicating that the predominant number of the sites available for dopant adsorption, which could impact the Fermi level of the SWCNTs, are already occupied. 


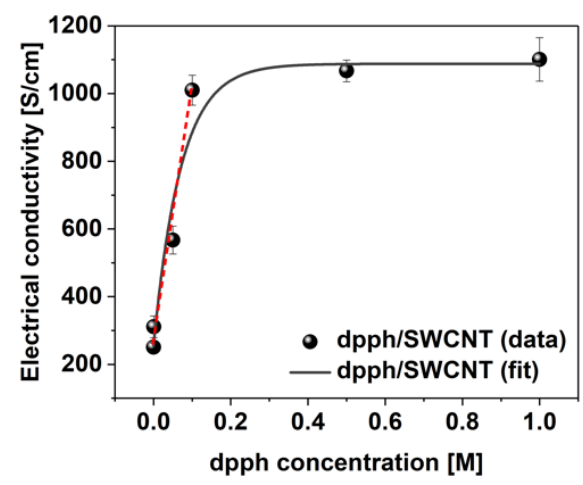

Figure 6. Electrical conductivity values of the SWCNT films before and after doping with dpph as a function of dopant concentration.

\section{Conclusions}

In summary, we illustrated how the presence of organophosphorus compounds may be sensed by monitoring the electrical and thermoelectric properties of ensembles from SWCNTs. Four model dopants were evaluated-1,3-Bis(dimethylphosphino)propane (dmpp), 1,3-Bis(dicyclohexylphosphino)propane (dcpp), 1,3-Bis(diphenylphosphino)propane (dpp), and 1,6-Bis(diphenylphosphino)hexane (dpph) to unravel the electronic and structural parameters of an ideal chemical compound for this purpose. The results showed that dpph organophosphorus dopant improves the electrical conductivity four-fold and notably boosts the Seebeck coefficient of the material by changing its sign and increasing its absolute value. As a consequence, the power factor of the material was augmented by order of magnitude, i.e., from 60.27 to $467 \mu \mathrm{W} / \mathrm{m} \cdot \mathrm{K}^{2}$.

The crucial attribute of an effective organophosphorus dopant in this study turned out to be the presence of phenyl groups connected directly with the phosphorus atoms to donate the charge to SWCNTs in a facile manner. Simultaneously, the importance of a sufficiently long alkyl chain was demonstrated as the dopant needs to assume an appropriate conformation to promote the charge transfer.

This study showed that to tune the electrical and thermoelectric properties of SWCNTs effectively, the know-how of organic chemistry is indispensable. In light of the preceding, further molecular design may pave the way to the more effective exploitation of the opportunities provided by nanocarbon materials. Simultaneously, the progress gained in this area would also reveal how to sense phosphorous pollution with such materials in the most selective and sensitive fashion.

Author Contributions: Conceptualization, D.J.; data curation, D.J.; formal analysis, M.S., M.L. and D.J.; funding acquisition, M.L. and D.J.; investigation, M.S. and D.J.; methodology, D.J.; project administration, D.J.; resources, M.L. and D.J.; supervision, M.L. and D.J.; validation, M.L. and D.J.; visualization, D.J.; writing-original draft, M.S., M.L. and D.J. All authors have read and agreed to the published version of the manuscript.

Funding: D.J. would like to thank the National Centre for Research and Development, Poland (under the Leader program, Grant agreement LIDER/0001/L-8/16/NCBR/2017) for financial support of the research and the National Agency for Academic Exchange of Poland (under the Academic International Partnerships program, grant agreement PPI/APM/2018/1/0004) for sponsoring an internship at Aalto University, Finland and covering the cost of publishing the article.

Institutional Review Board Statement: Not applicable.

Informed Consent Statement: Not applicable.

Data Availability Statement: Data regarding this article is available from the corresponding author upon a reasonable request.

Conflicts of Interest: The authors declare no conflict of interest. 


\section{References}

1. Monthioux, M.; Kuznetsov, V.L. Who Should Be Given the Credit for the Discovery of Carbon Nanotubes? Carbon 2006, 44, 1621-1623. [CrossRef]

2. Iijima, S. Helical Microtubules of Graphitic Carbon. Nature 1991, 354, 56-58. [CrossRef]

3. Novoselov, K.S.; Geim, A.K.; Morozov, S.V.; Jiang, D.; Zhang, Y.; Dubonos, S.V.; Grigorieva, I.V.; Firsov, A.A. Electric Field Effect in Atomically Thin Carbon Films. Science 2004, 306, 666-669. [CrossRef]

4. Bandaru, P.R. Electrical Properties and Applications of Carbon Nanotube Structures. J. Nanosci. Nanotechnol. 2007, 7, 1239-1267. [CrossRef] [PubMed]

5. Marinho, B.; Ghislandi, M.; Tkalya, E.; Koning, C.E.; de With, G. Electrical Conductivity of Compacts of Graphene, Multi-Wall Carbon Nanotubes, Carbon Black, and Graphite Powder. Powder Technol. 2012, 221, 351-358. [CrossRef]

6. Kholmanov, I.N.; Magnuson, C.W.; Aliev, A.E.; Li, H.; Zhang, B.; Suk, J.W.; Zhang, L.L.; Peng, E.; Mousavi, S.H.; Khanikaev, A.B.; et al. Improved Electrical Conductivity of Graphene Films Integrated with Metal Nanowires. Nano Lett. 2012, 12, 5679-5683. [CrossRef] [PubMed]

7. Coleman, J.N.; Khan, U.; Blau, W.J.; Gun'ko, Y.K. Small but Strong: A Review of the Mechanical Properties of Carbon NanotubePolymer Composites. Carbon 2006, 44, 1624-1652. [CrossRef]

8. Ranjbartoreh, A.R.; Wang, B.; Shen, X.; Wang, G. Advanced Mechanical Properties of Graphene Paper. J. Appl. Phys. 2011, 109, 014306. [CrossRef]

9. Papageorgiou, D.G.; Kinloch, I.A.; Young, R.J. Mechanical Properties of Graphene and Graphene-Based Nanocomposites. Prog. Mater. Sci. 2017, 90, 75-127. [CrossRef]

10. Kumanek, B.; Janas, D. Thermal Conductivity of Carbon Nanotube Networks: A Review. J. Mater. Sci. 2019, 54, 7397-7427. [CrossRef]

11. Balandin, A.A.; Ghosh, S.; Bao, W.; Calizo, I.; Teweldebrhan, D.; Miao, F.; Lau, C.N. Superior Thermal Conductivity of Single-Layer Graphene. Nano Lett. 2008, 8, 902-907. [CrossRef]

12. Guo, Z.-X.; Zhang, D.; Gong, X.-G. Thermal Conductivity of Graphene Nanoribbons. Appl. Phys. Lett. 2009, 95, 163103. [CrossRef]

13. John, R.; Merlin, B. Optical Properties of Graphene, Silicene, Germanene, and Stanene from IR to Far UV-A First Principles Study. J. Phys. Chem. Solids 2017, 110, 307-315. [CrossRef]

14. Lin, M.F.; Shung, K.W.-K. Plasmons and Optical Properties of Carbon Nanotubes. Phys. Rev. B 1994, 50, 17744-17747. [CrossRef] [PubMed]

15. Kataura, H.; Kumazawa, Y.; Maniwa, Y.; Umezu, I.; Suzuki, S.; Ohtsuka, Y.; Achiba, Y. Optical Properties of Single-Wall Carbon Nanotubes. Synth. Met. 1999, 103, 2555-2558. [CrossRef]

16. Falkovsky, L.A. Optical Properties of Graphene. J. Phys. Conf. Ser. 2008, 129, 012004. [CrossRef]

17. Huang, G.; Hou, C.; Shao, Y.; Wang, H.; Zhang, Q.; Li, Y.; Zhu, M. Highly Strong and Elastic Graphene Fibres Prepared from Universal Graphene Oxide Precursors. Sci. Rep. 2014, 4, 4248. [CrossRef] [PubMed]

18. Lu, J.P. Elastic Properties of Carbon Nanotubes and Nanoropes. Phys. Rev. Lett. 1997, 79, 1297-1300. [CrossRef]

19. Blackburn, J.L.; Ferguson, A.J.; Cho, C.; Grunlan, J.C. Carbon-Nanotube-Based Thermoelectric Materials and Devices. Adv. Mater. 2018, 30, 1704386. [CrossRef]

20. Bulmer, J.S.; Lekawa-Raus, A.; Rickel, D.G.; Balakirev, F.F.; Koziol, K.K. Extreme Magneto-Transport of Bulk Carbon Nanotubes in Sorted Electronic Concentrations and Aligned High Performance Fiber. Sci. Rep. 2017, 7, 12193. [CrossRef] [PubMed]

21. He, X.; Gao, W.; Xie, L.; Li, B.; Zhang, Q.; Lei, S.; Robinson, J.M.; Hároz, E.H.; Doorn, S.K.; Wang, W.; et al. Wafer-Scale Monodomain Films of Spontaneously Aligned Single-Walled Carbon Nanotubes. Nat. Nanotechnol. 2016, 11, 633-638. [CrossRef]

22. Komatsu, N.; Nakamura, M.; Ghosh, S.; Kim, D.; Chen, H.; Katagiri, A.; Yomogida, Y.; Gao, W.; Yanagi, K.; Kono, J. GrooveAssisted Global Spontaneous Alignment of Carbon Nanotubes in Vacuum Filtration. Nano Lett. 2020, 20, 2332-2338. [CrossRef]

23. Sun, W.; Shen, J.; Zhao, Z.; Arellano, N.; Rettner, C.; Tang, J.; Cao, T.; Zhou, Z.; Ta, T.; Streit, J.K.; et al. Precise Pitch-Scaling of Carbon Nanotube Arrays within Three-Dimensional DNA Nanotrenches. Science 2020, 368, 874-877. [CrossRef] [PubMed]

24. Zhao, M.; Chen, Y.; Wang, K.; Zhang, Z.; Streit, J.K.; Fagan, J.A.; Tang, J.; Zheng, M.; Yang, C.; Zhu, Z.; et al. DNA-Directed Nanofabrication of High-Performance Carbon Nanotube Field-Effect Transistors. Science 2020, 368, 878-881. [CrossRef] [PubMed]

25. Meunier, V.; Sumpter, B.G. Amphoteric Doping of Carbon Nanotubes by Encapsulation of Organic Molecules: Electronic Properties and Quantum Conductance. J. Chem. Phys. 2005, 123, 024705. [CrossRef]

26. Nonoguchi, Y.; Tani, A.; Murayama, T.; Uchida, H.; Kawai, T. Surfactant-Driven Amphoteric Doping of Carbon Nanotubes. Chem. Asian J. 2018, 13, 3942-3946. [CrossRef]

27. Kamarás, K.; Pekker, Á.; Botka, B.; Hu, H.; Niyogi, S.; Itkis, M.E.; Haddon, R.C. The Effect of Nitric Acid Doping on the Optical Properties of Carbon Nanotube Films. Phys. Status Solidi 2010, 247, 2754-2757. [CrossRef]

28. Zhou, W.; Vavro, J.; Nemes, N.M.; Fischer, J.E.; Borondics, F.; Kamaras, K.; Tanner, D. Charge Transfer and Fermi Level Shift in P-Doped Single-Walled Carbon Nanotubes. Phys. Rev. B 2005, 71, 205423. [CrossRef]

29. Lee, R.S.; Kim, H.J.; Fischer, J.E.; Thess, A.; Smalley, R.E. Conductivity Enhancement in Single-Walled Carbon Nanotube Bundles Doped with K and Br. Nature 1997, 388, 255-257. [CrossRef]

30. Zhao, Y.; Wei, J.; Vajtai, R.; Ajayan, P.M.; Barrera, E.V. Iodine Doped Carbon Nanotube Cables Exceeding Specific Electrical Conductivity of Metals. Sci. Rep. 2011, 1, 83. [CrossRef] 
31. Ayala, P.; Arenal, R.; Rümmeli, M.; Rubio, A.; Pichler, T. The Doping of Carbon Nanotubes with Nitrogen and Their Potential Applications. Carbon 2010, 48, 575-586. [CrossRef]

32. Klinke, C.; Chen, J.; Afzali, A.; Avouris, P. Charge Transfer Induced Polarity Switching in Carbon Nanotube Transistors. Nano Lett. 2005, 5, 555-558. [CrossRef]

33. Schmid, M.; Goze-Bac, C.; Krämer, S.; Roth, S.; Mehring, M.; Mathis, C.; Petit, P. Metallic Properties of Li-Intercalated Carbon Nanotubes Investigated by NMR. Phys. Rev. B 2006, 74, 073416. [CrossRef]

34. Nonoguchi, Y.; Ohashi, K.; Kanazawa, R.; Ashiba, K.; Hata, K.; Nakagawa, T.; Adachi, C.; Tanase, T.; Kawai, T. Systematic Conversion of Single Walled Carbon Nanotubes into N-Type Thermoelectric Materials by Molecular Dopants. Sci. Rep. 2013, 3 , 3344. [CrossRef]

35. Carpenter, S.R.; Caraco, N.F.; Correll, D.L.; Howarth, R.W.; Sharpley, A.N.; Smith, V.H. Nonpoint Pollution of Surface Waters with Phosphorus and Nitrogen. Ecol. Appl. 1998, 8, 559-568. [CrossRef]

36. Garnache, C.; Swinton, S.M.; Herriges, J.A.; Lupi, F.; Stevenson, R.J. Solving the Phosphorus Pollution Puzzle: Synthesis and Directions for Future Research. Am. J. Agric. Econ. 2016, 98, 1334-1359. [CrossRef]

37. Conley, D.J.; Paerl, H.W.; Howarth, R.W.; Boesch, D.F.; Seitzinger, S.P.; Havens, K.E.; Lancelot, C.; Likens, G.E. Controlling Eutrophication: Nitrogen and Phosphorus. Science 2009, 323, 1014-1015. [CrossRef] [PubMed]

38. Correll, D.L. The Role of Phosphorus in the Eutrophication of Receiving Waters: A Review. J. Environ. Qual. 1998, 27, 261-266. [CrossRef]

39. Giordano, C.; Filatrella, G.; Sarno, M.; Bartolomeo, A.D. Multi-Walled Carbon Nanotube Films for the Measurement of the Alcoholic Concentration. Micro Nano Lett. 2019, 14, 304-308. [CrossRef]

40. Panes-Ruiz, L.A.; Shaygan, M.; Fu, Y.; Liu, Y.; Khavrus, V.; Oswald, S.; Gemming, T.; Baraban, L.; Bezugly, V.; Cuniberti, G. Toward Highly Sensitive and Energy Efficient Ammonia Gas Detection with Modified Single-Walled Carbon Nanotubes at Room Temperature. ACS Sens. 2018, 3, 79-86. [CrossRef]

41. Liu, B.; Liu, X.; Yuan, Z.; Jiang, Y.; Su, Y.; Ma, J.; Tai, H. A Flexible NO2 Gas Sensor Based on Polypyrrole/Nitrogen-Doped Multiwall Carbon Nanotube Operating at Room Temperature. Sens. Actuators B Chem. 2019, 295, 86-92. [CrossRef]

42. Rushi, A.D.; Datta, K.P.; Ghosh, P.S.; Mulchandani, A.; Shirsat, M.D. Functionalized carbon nanotubes for detection of volatile organic pollutant. In Perspective of Carbon Nanotubes; IntechOpen: London, UK, 2019.

43. Norizan, M.N.; Moklis, M.H.; Demon, S.Z.N.; Halim, N.A.; Samsuri, A.; Mohamad, I.S.; Knight, V.F.; Abdullah, N. Carbon Nanotubes: Functionalisation and Their Application in Chemical Sensors. RSC Adv. 2020, 10, 43704-43732. [CrossRef]

44. Rdest, M.; Janas, D. Effective Doping of Single-Walled Carbon Nanotubes with Polyethyleneimine. Materials 2021, $14,65$. [CrossRef]

45. Hanwell, M.D.; Curtis, D.E.; Lonie, D.C.; Vandermeersch, T.; Zurek, E.; Hutchison, G.R. Avogadro: An Advanced Semantic Chemical Editor, Visualization, and Analysis Platform. J. Cheminform. 2012, 4, 17. [CrossRef] [PubMed]

46. Costa, S.; Borowiak-Palen, E.; Kruszynska, M.; Bachmatiuk, A.; Kalenczuk, R. Characterization of Carbon Nanotubes by Raman Spectroscopy. Mater. Sci. Pol. 2008, 26, 433-441.

47. Janas, D. Powerful Doping of Chirality-Sorted Carbon Nanotube Films. Vacuum 2018, 149, 48-52. [CrossRef]

48. Lekawa-Raus, A.; Kurzepa, L.; Kozlowski, G.; Hopkins, S.C.; Wozniak, M.; Lukawski, D.; Glowacki, B.A.; Koziol, K.K. Influence of Atmospheric Water Vapour on Electrical Performance of Carbon Nanotube Fibres. Carbon 2015, 87, 18-28. [CrossRef] 